\title{
International Academy of The Environment: An Executive Summary
}

\section{Background and Mandate}

The International Academy of the Environment, an independent Swiss Foundation, is one of the first organizations wholly dedicated to education, training, interdisciplinary research, and policy formulation, in environment and development issues. The Academy has a distinguished international Governing Council, and is supported by the Swiss federal Government, the Canton of Geneva, and the University of Geneva, in cooperation with United Nations organizations. The campus of the Academy is beautifully situated in wooded parkland on the outskirts of Geneva. The Academy expects to benefit both from Geneva's history as an international centre and from the Swiss spirit of cooperation.

The work of the Academy rests on the knowledge that environmental problems today are international in character and intrinsically connected to other important global issues such as development and human population. The Academy was created in 1991 as an independent international institution to serve as a focal point and meeting ground for environmental management, education, and thinking - at once for the public and private sectors, academia, and nongovernmental and intergovernmental organizations. It provides comparison and exchange of the best practices in regional, national, and local, management of environmental issues, and offers a forum for the dialogue and collaboration that are essential to address those issues effectively.

The Academy seeks to facilitate the development of concrete solutions to specific environmental problems, and brings together decision-makers from developing as well industrialized countries in translating such solutions into practice. It is the philosophy of the Academy that its programmes be interdisciplinary, international, and relevant to the needs of decision-makers.

\section{Overview of Current Programmes and Activities}

The activities of the Academy will aim to combine the best aspects of universities, business schools, and policy institutes, by integrating applied research, education programmes, executive seminars, and a publications and communications programme to create a dynamic environment for learning.

In the immediate future, the Academy will focus on the following activities:

\section{A. The Development of Educational Courses Offering a Broad Perspective on Environment and Devel- opment}

The Academy sees it as essential to develop a broad curriculum in environmental management in order to provide a general overview on the complex linkages and interdependences involved in environment and development issues. The framework developed for this curriculum will be used for courses ranging from a few days (for executives) to one year in length, and will provide a sound grounding in the latest thinking on environment and development, while also introducing the emerging issues and trends that will become a central part of the debate in the coming decades.
The curriculum is being developed with experts from the United Nations system, governments, academia, the private-sector, and environmental organizations. It will cover:

- Basic concepts, such as population dynamics, ecological systems, natural resources, human ecology, and linkages between environment and development.

- Key environmental problems, such as global change, forests and biodiversity, freshwater resources, ocean pollution, energy, and soil erosion.

- Environmental management tools, such as environmental auditing, legislation and regulation, and environmental impact assessment.

B. Seminars and Interdisciplinary Research Around Specific Themes in Environment and Development

The Academy will develop interdisciplinary research agendas around a number of key themes that will be selected in the light of existing international efforts and emerging priorities, including those that are being debated within the United Nations Conference on Environment and Development (UNCED) process. The Academy will thus contribute to an interdisciplinary analysis, oriented towards assisting beneficial policy-development in government and industry.

This interdisciplinary analysis will serve as the framework for designing short seminars targeted at decisionmakers from both developing and industrialized countries. Formal classroom teaching is kept to a minimum, and programmes emphasize interactive and collaborative methods and the use of case-studies. A key element of this approach is that classes and meetings are designed for mixed audiences of senior individuals from government, business, academia, and environmental organizations, who will benefit from the exchange of widely diverse perspectives.

\section{The Establishment of a Postgraduate Visiting Fel- lowship Programme for Developing Countries}

Promising young environmental managers and research workers from less-developed countries will be invited to spend periods of time working at the Academy. We expect that this programme will result in these people becoming better able than formerly to integrate themselves into the international environment and development community, as well to build on their knowledge of current academic and political thinking. In addition, the Academy will work with these visiting fellows to update and enhance its own environmental and development training and research programmes.

\section{Other Activities will Include Scientific Workshops, a Publications Group, and Networking and Information Exchange Services}

The Academy will promote and play host to scientific workshops, particularly where such workshops support the interdisciplinary research agenda of the Academy. The aim will be to focus on applied research and to bring this research into the realm of the policymaker. In this way it is hoped that scientists will become more aware of the 
potential policy-implications of their work, and that policymaking can proceed from a sound research base.

The publications group at the Academy will focus on providing access to training and curriculum materials for like-minded research institutes around the world. In addition, the results of the programmes and interdisciplinary research at the Academy will be communicated through newsletters, journal articles, executive summaries, and final reports of seminars.

The Academy endeavours to assume an active role in the establishment of international networks for exchange of environment and development information to scientists, policymakers, and like-minded training institutes. As well, the Academy will facilitate due access to data on the global environment in an effort to promote its use in interdisciplinary research and decision-making processes.

\section{Geneva: A World Environment Centre}

Geneva has a long tradition as a centre of international affairs; it is a place where agendas are set, multilateral treaties are negotiated, and conflicts are resolved. This has long been true for issues of war and peace, humanitarian aid, and economic policy. Geneva and its region are also playing an active role in addressing international environmental problems. This is demonstrated by the fact that there are numerous organizations with world-wide environmental interests located in the region.

The establishment of the International Academy of The Environment should be viewed as a new initiative in the general evolution of Geneva and the Lake Léman region as an important centre for global environmental concerns. The Academy is designed to serve as a centre for environmental management education and thinking. It organizes its programmes to serve best its international audience by working closely with the broad range of institutional resources and expertise present in the Geneva region.

\section{Organization}

The International Academy of the Environment was incorporated as a foundation on 22nd April 1991. On 1st July 1992, the Swiss Federal Council formally recognized the Academy as an institution of higher learning under the Federal Law on Universities, thereby entitling it to Federal subsidies. At the same time, the Federal Council endorsed the Governing Council of the Academy (Conseil de Fondation de l'Académie*), which includes representatives from the Swiss Government, the Government of the Canton of Geneva, the University of Geneva, the private sector, nongovernmental organizations, and other universities and international organizations.

The Academy budget will be of the order of 6.6 million SF in 1992, rising to a projected 8 million SF in 1994 not including rental income from its real estate. The financing for 1991 for the Academy was assured by the University of Geneva and ad hoc subsidies from the Swiss Confederation (aid for developing countries, continued education, aid to Eastern European Countries, and others). The contributions from the Confederation and the Canton of Geneva are to be institutionalized, starting in 1992. In addition, the Academy will rely on matched support from international agencies, government ministries, the private sector, foundation grants, and fees for programmes targeted at industrialized countries.

HE Flavio COTTI, Honorary President,
DOMINIQUE FÖLLMI, Chairman
$\&$
BERNARD GIOVANNINI, Director
International Academy of the Environment
4 Chemin de Conches
CH-1231 Conches-Geneva
Switzerland.

* The official language of which is English. — Ed.

\section{The Morelia Declaration on the Need for an International Court of the Environment}

A remarkable exchange took place recently in Mexico when leading environmentalists and other scientists, representatives from native tribes of North and South America, political activists, and writers - in all from 20 countries - spent a week together at Morelia discussing the state of the world as we approach the end of the millennium. Independently, but without exception, each participant expressed concern that life on our planet is in grave danger. Noting that:

* 24 thousand million tons of topsoil from cropland are being lost every year. If deforestation and other forms of land erosion continue at the current rate, the scientists present stated that, by the end of the decade, the Earth will have no additional farmland but a projected nearly one thousand million additional mouths to feed;

* The nuclear disaster of Chernobyl in 1986, which in varying degrees has subjected over 35 million people to radioactive assault, was only one of more than 100 nuclear accidents which took place over the last decade. At Morelia the scientist responsible for the clean-up of Chernobyl stated his belief that at least three nuclear catastrophes on the scale of Chernobyl are likely to take place by AD 2000;

* Seventy per cent of the world's population lives within 100 miles of the sea. The profligate use of fossil fuels, especially by the industrialized world, is rapidly and irreversibly changing the global climate. Experts stressed that continued rising sea-levels and global warming will lead to massive flooding of coastal areas, creating millions of new environmental refugees on an even greater scale than we witness annually in countries such as Bangladesh; and

* Equable human survival depends inter alia on biological diversity. At current rates of environmental destruction - especially the wanton destruction of tropical forests in the Americas, Asia, and Africa - we may lose more than a million species within the next ten years, and a quarter of all living species within the next fifty years, accordingly.

I. We, the participants of the Morelia Symposium, urge the leaders of the world at the Earth Summit to be held in June 1992 in Rio de Janeiro, Brazil, to commit themselves to ending ecocide and ethnocide, and we propose the creation of an International Court of the Environment, modelled on the International Court of Justice at The Hague. ${ }^{\dagger}$

\footnotetext{
Might this not be located most appropriately in Geneva, Switzerland, with its unique 'environment' of international organizations and demonstrated capability of accommodating them - as indicated in the recent booklet entitled Geneva and the Environment: A Guide to International Activity and Organisations, published by the International Academy of the Environment, 4 Chemin de Conches, 1231 Geneva, Switzerland: $x i+73$ pp., 1992, and available on request from the Academy. - Ed.
} 